\title{
Mongolism and Sex: A Common Problem of Cell Proliferation?
}

\author{
URSULA MITTWOCH
}

From the Galton Laboratory, University College, London, Wolfson House, 4 Stephenson Way, London NW1 $2 H E$

It is now evident that variations in chromosome constitution may have a profound effect on physical and mental development, both normal and pathological. Mongolism is the best known example of a severe congenital abnormality caused by the presence of an additional chromosome; while a difference in the sex chromosome constitution- $X Y$ in the male and $\mathrm{XX}$ in the female-produces the most far-reaching normal variation in human beings and other animal species.

In spite of the spectacular progress in our knowledge of human chromosomes during the past 15 years, there is as yet no working hypothesis relating cause and effect; in other words, we need an answer to the question: 'By what mechanism do different chromosome constitutions result in different end products of development ?'

\section{Theory of Genic Balance}

The usual explanation has recourse to the theory of genic balance, which was developed by Bridges (1939) in order to explain differences in the chromosome constitution of the fruitfly, Drosophila melanogaster, and their relation to the phenotype of the flies. Originally formulated in relation to flies with a wrong number of small autosomes, the theory was extended to explain the process of sex determination.

The central idea underlying the theory of genic balance is that each character of the adult is the result of the joint action of all the genes in the entire complement of chromosomes. Some of these genes tend to increase the development of the character in question ('plus genes'), while others have the opposite effect ('minus genes'). If the chromosomes differ in the net contents of the genes which they carry, it follows that a difference in the end point or balance might be achieved not only through gene mutation but also through the addition or loss of an entire chromosome.

Received 13 April 1971.
Applied to the process of sex determination, the theory postulates large numbers of male and female determining genes present in both sexes. Normally, the sex chromosome constitution ensures is that the genes for one sex outweigh those of the 0 other. In the human species, male determining genes on the Y-chromosome would be assumed to 3 outbalance the female determining genes on the other chromosomes. However, no real evidence for the existence of such genes has been forthcoming in man, while in Drosophila repeated searches for the presence of male and female determining genes on the various chromosomes have been unsuccessful (Mittwoch, 1964, 1967a and b, and 1969).

\section{Aneuploidy and Growth Retardation}

It does not seem likely that the abnormalities associated with trisomy can be accounted for by the presence of genes on the additional chromosome. The most thorough study of trisomy available was carried out by Blakeslee on a flowering plant, the Jimson weed, Datura stramonium (see Avery, Satina, and Rietsma, 1959). This species has 12 pairs of chromosomes and all 12 trisomics have been produced and analysed. Each one was distinguishable by specific morphological features. Moreover, each one was slower in growth than normal plants; and on the theory of genic balance this would seem to require the unlikely assumption that all 12 chromosomes carry an excess of genes for slow growth.

Delayed growth is characteristic also in mongolism (Penrose and Smith, 1966) and other human trisomies (Taylor, 1968); Hall (1965 and 1966) suggested that the similarities in clinical features seen in the three human trisomy syndromes might be due to delayed development, owing to a lowering of the rate of cell multiplication. Also, normal females have a lower birth weights than males (Tanner, Whitehouse, and Takaishi, 1966). If one 
made the assumption that different chromosome constitutions are associated with different rates of growth, a number of recent findings may provide a clue towards an explanation.

In root tips of rye plants, the mitotic cycle time is increased by the presence of supernumerary B chromosomes (Ayonoadu and Rees, 1968). In several species of plants the mitotic cycle time, and particularly the period of DNA synthesis, were found to be proportional to the amount of DNA present (Van't Hof, 1965); and even though this relationship may not be applicable in all individual instances (see Yang and Dodson, 1970), a general tendency in this direction is likely to exist. Its applicability to mammalian cells was suggested by Goldfeder (1965) with special reference to spindle cell tumours; and Lennartz, Schümmelfeder, and Maurer (1966) reported that ascites tumour cells with tetraploid karyotypes required about twice as long to complete DNA synthesis as diploid ascites cells.

Of particular relevance in this connexion are recent findings on cultured cells from patients with mongolism which suggest that the process of DNA synthesis may be slowed down or inhibited in cells with mongol karyotypes, both in fibroblasts (Mittwoch, 1967c; Kaback and Bernstein, 1970) and in lymphocytes (Mellman, Younkin, and Baker, 1970). If a slowing down of the mitotic cycle should prove to be a general feature characteristic of the mongol karyotype, in vivo as well as in vitro, it might go a considerable way towards explaining the observed retardation of growth associated with the syndrome. Indeed, since subnormal numbers of cells in different organs have been reported not only in newborn mongols but also in trisomies D and $E$ (Naeye, 1967), the question arises whether similar delays in cell cycle times may occur in the other two autosomal trisomies.

Turning to the sex chromosomes, another finding of great potential importance is that in $45, \mathrm{X}$ cells, the mitotic cycle time may be shorter than in normal male and female cells (Polani, 1970). Thus, although the second X-chromosome of normal females as well as the $\mathrm{Y}$-chromosome of males are largely heterochromatic, it is possible that these chromosomes, too, may affect mitotic cycle times. Confirmation for this idea may be seen in the fact that the total ridge count of the fingers is progressively decreased both by additional sex chromosomes (Penrose, 1968 and 1969) and in mongolism (Holt, 1968 and 1970): for the ridge may be regarded as a permanent characteristic which is related to the growth attained by the embryo in the 4th intrauterine month.

\section{Differential Growth}

While it is fairly safe to assume that a lengthening of the mitotic cycle time would lead to a slowing down of the rate of cell proliferation and, therefore, to a retardation of growth, it is far more difficult to understand how the differential rates of cell multiplication, which are so striking a feature of many phases of embryogenesis (Weiss, 1955), should be affected by different chromosome constitutions. Two recent lines of research may help to provide a possible way out of our almost total ignorance in this field.

(1) The chromosomes of bean plants (Vicia faba) have been shown to vary considerably in volume in different tissues and this variation was positively correlated with nuclear volume and with different mitotic rates (Bennett, 1970). The importance of increasing nuclear volumes as a prerequisite to cell division has also been emphasized in connection with experiments involving the fusion of hen erythrocytes with $\mathrm{HeLa}$ cells (Harris, 1970). In beans, differences in nuclear volumes were correlated with the amounts of RNA, total protein, and nuclear histones, the amount of DNA remaining constant. These findings suggest the possibility that varying proportions of the DNA of chromosomes may be required to form complexes with RNA and protein and that these different complexes are related to different mitotic rates.

(2) The possibility that specific chromosomal regions differ in their activity in different developmental stages is suggested by the findings on chromosome puffs in the giant chromosomes of Drosophila and other Diptera. These puffs are localized protruberances of the chromosomes which are especially active in RNA synthesis. The puffing pattern varies in different developmental stages and in different tissues of the larvae (Beermann, 1967).

It is thus conceivable that, say, the addition of a particular chromosome to the normal karyotype has not only a general effect on the length of the mitotic cycle, but it might also, by virtue of its normally enhanced activity in particular cells at a certain developmental stage, exert a more specific effect on the differential mitotic rate at this stage.

\section{Additional DNA and the Mitotic Cycle}

The notion that the addition to the karyotype of further chromosomes or chromosomal regions may affect mitotic cycle time and rates of cell proliferation would seem to be relevant to current discussions on the organization of the mammalian genome. So far, the function of most of the highly repeated sequences of DNA, which are now known 
to make up a considerable part of the chromosomes of higher organisms (Britten and Kohne, 1969a and b), is unknown. It has recently been suggested that satellite DNA may be conferring an advantage on the chromosomes in meiosis (Walker, 1971). It must, however, be remembered that before a chromosome can be tested in meiosis, it has to undergo a large number of mitoses. If a change in the chromosome were to result in an alteration in the length of the mitotic cycle, a pronounced effect on the phenotype might be expected.

\section{Heterochromatin}

Satellite DNA is located in the heterochromatic regions of chromosomes (Jones, 1970) and there is evidence in Drosophila and plants that heterochromatic chromosomes and chromosomal regions affect quantitatively variable characters (Mather, 1949). It seems likely that the underlying basis of a phenotypic difference such as the number of abdominal bristles in Drosophila is a difference in cell growth and proliferation. Differences in euchromatic regions of chromosomes might be expected to have similar effects, but such differences tend to be much less well tolerated by the organism (Brown, 1966). The finding that in rodents, heterochromatin requires less time for DNA synthesis than euchromatin (Schmid and Leppert, 1969) suggests a possible reason why differences in heterochromatin may be less disruptive to the cell cycle than differences in euchromatin.

Of the two human chromosomes, Nos. 21 and 22, neither is very late replicating (German, 1964), and both are likely to contain euchromatin as well as heterochromatin. We may postulate that the presence of an additional No. 21 chromosome causes a lengthening of the mitotic cycle and a generalized inhibition of cell proliferation; certain development stages may be particularly affected. As regards the difference in sex chromosomes between normal males and females, both the second $\mathrm{X}$-chromosome of females as well as the $\mathrm{Y}$-chromosome of males are typically late replicating (German, 1964) and they may both be regarded as largely heterochromatic. The difference in mitotic cycle time between normal karyotypes with $\mathrm{XX}$ and $\mathrm{XY}$ chromosomes may be expected to be slight. I have previously postulated that the rate of cell proliferation may be slightly higher in mammalian males than in females; and that at a given stage in development, possibly in cells of the gonadal rudiment, the presence of a Y-chromosome causes an additional spurt of cell division, as a result of which the rudiment develops into a testis (Mittwoch, 1969 and 1970a and b). In accordance with this postu- $\Omega$ late, gonadal rudiments of chromosomal males $\stackrel{D}{\stackrel{D}{\circ}}$ have been shown to grow significantly faster than $\stackrel{\mathbb{P}}{-}$ those of their female litter mates in rats (Lindh, 1961; Mittwoch, Dellanty, and Beck, 1969) and in $\frac{\text { ? }}{6}$ golden hamsters (Lindh, 1961). These findings fit in with the now generally accepted idea that the $\frac{\bar{c}}{\mathrm{c}}$. mammalian ovary represents the neutral gonad, $\vec{\Phi}$ which develops (for a time) even in Turner's syn- $\varrho$ drome with an XO sex chromosome constitution के (Singh and Carr, 1966). In order to develop into a $\overrightarrow{0}$ testis, however, a Y-chromosome must be present $\overrightarrow{-}$ and the gonadal rudiment may need to reach a $\vec{\omega}$ certain size before a given stage of development, when the embryonic testis becomes a secretor of androgens (Jost, 1965).

Sex chromosomes are thought to have originated $\overrightarrow{\hat{i}_{0}}$ from an ordinary pair of homologous chromosomes, $N$ which have become dimorphic in the course of evolution (Darlington, 1958; Ohno, 1967). At $\vec{z}$ the same time they have tended to become heterochromatic and this may be relevant to the attain- $\frac{\widehat{O}}{\square}$ ment of two different karyotypes associated with two $\vec{\bullet}$ physiological developmental rates. By contrast, the mongol karyotype has not had a chance of being thus modified during evolution and the addition of an extra chromosome 21 results in a developmental rate which is abnormal.

Although the problems regarding control mechanisms of cell growth and cell proliferation in embryo- $\stackrel{\varnothing}{\propto}$ genesis may seem formidable, it is clearly necessary $\overrightarrow{\overrightarrow{0}}$ to come to grips with them before any comprehen- 3 sive theory relating genetic endowment with ultimate phenotype can be attempted. The results of recent work hold out the promise that it may be possible to correlate differences in chromosome constitution with differences in embryonic growth, and that these, in turn, may be related to changes in the phenotype both normal and pathological.

\section{Summary}

Evidence is presented that different chromosome $\frac{D}{O}$ constitutions may affect mitotic cycle times and hence the rates of cell proliferation. The presence o of an additional chromosome in mongolism is likely $N$ to slow down mitotic cycle times. The sex ్N chromosome dimorphism may result in a slight overall increase in cell growth of XY compared with $\mathrm{XX}$ cells, as well as in a more pronounced increase of $\frac{}{\overparen{D}}$ mitoses in cells of the male gonadal rudiment.

\section{REFERENCES}

Avery, A. G., Satina, S., and Rietsma, J. (editors) (1959). Blakeslee: The Genus Datura. Ronald Press, New York.

Ayonoadu, U. W. and Rees, H. (1968). The regulation of mitosis by B-chromosomes in rye. Experimental Cell Research, 52, 284-290. 
Beermann, W. (1967). Gene action at the level of the chromosome. In Heritage from Mendel, pp. 179-201, ed. by R. A. Brink. University of Wisconsin Press, Madison, Milwaukee, and London.

Bennett, M. D. (1970). Natural variation in nuclear characters of meristems in Vicia faba. Chromosoma, 29, 317-335.

Bridges, C. B. (1939). Cytological and genetic basis of sex. In Sex and Internal Secretions 2nd edition, pp. 15-63, ed. by E. Allen. Baillère, London.

Britten, R. J. and Kohne, D. E. (1969a). Repetition of nucleotide sequences in chromosomal DNA. In Handbook of Molecular Cytology, pp. 22-36, ed. by A. Lima-de-Faria. North Holland, Amsterdam.

Britten, R. J. and Kohne, D. E. (1969b). Implications of repeated nucleotide sequences. In Handbook of Molecular Cytology, pp. 3751, ed. by A. Lima-de-Faria. North Holland, Amsterdam.

Brown, S. W. (1966). Heterochromatin. Science, 151, 417-425.

Darlington, C. D. (1958). Evolution of Genetic Systems. Oliver and Boyd, Edinburgh.

German, J. (1964). The pattern of DNA synthesis in the chromosomes of human blood cells. Fournal of Cell Biology, 20, 37-55.

Goldfeder, A. (1965). Biological properties and radiosensitivity of tumours: determination of the cell-cycle and time of synthesis of deoxyribonucleic acid using tritiated thymidine and autoradiography. Nature, 207, 612-614.

Hall, B. (1965). Delayed ontogenesis in human trisomy syndromes. Hereditas, Genetiskt Arkiv, 52, 334-344.

Hall, B. (1966). Follow up investigation of newborn mongoloids with respect to growth retardation. Hereditas, Genetiskt Arkiv, 56, 99-108.

Harris, H. (1970). Cell Fusion. Clarendon Press, Oxford.

Holt, S. B. (1968). The Genetics of Dermal Ridges. Thomas, Springfield, Illinois.

Holt, S. B. (1970). Dermatoglyphics in mongolism. Annals of the New York Academy of Sciences, 171, 602-616.

Jones, K. W. (1970). Chromosomal and nuclear location of mouse satellite DNA in individual cells. Nature, 225, 912-915.

Jost, A. (1965). Gonadal hormones in the sex differentiation of the mammalian fetus. In Organogenesis, pp. 611-628, ed. by R. L. de Haan and H. Ursprung. Holt, Rinehart and Winston, New York.

Kaback, M. M. and Bernstein, L. H. (1970). Biologic studies of trisomic cells growing in vitro. Annals of the New York Academy of Sciences, 171, 526-536.

Lennartz, K. J., Schümmelfeder, N., and Maurer, W. (1966). Dauer der DNA-Synthesephase bei Ascitestumoren der Maus unterschiedlicher Ploidie. Naturwissenschaften, 53, 21-22.

Lindh, J. (1961). Quantitative Aspects of Prenatal Growth in Albino Rat and Golden Hamster Studied by Morphologic and Experimental Methods. Thesis, Department of Anatomy, Lund.

Mather, K. (1949). Biometrical Genetics. Methuen, London.

Mellman, W. J., Younkin, L. H., and Baker, D. (1970). Abnormal lymphocyte function in trisomy 21. Annals of the New York Academy of Sciences, 171, 537-542.

Mittwoch, U. (1964). Sex chromosomes and sex chromatin. Nature, 204, 1032-1034.
Mittwoch, U. (1967a). Sex Chromosomes. Academic Press, New York and London.

Mittwoch, U. (1967b). Sex differentiation in mammals. Nature, 214, 554-556.

Mittwoch, U. (1967c). DNA synthesis in cells grown in tissue culture from patients with mongolism. In Mongolism, pp. 51-61, ed. by G. E. W. Wolstenholme and R. Porter. Churchill, London.

Mittwoch, U. (1969). Do genes determine sex ? Nature, 221, 446448.

Mittwoch, U. (1970a). How does the Y chromosome affect gonadal differentiation? Philosophical Transactions of the Royal Society B, 259, 113-117.

Mittwoch, U. (1970b). The mammalian Y-chromosome and gonadal differentiation. Bulletin of the European Society of Human Genetics, 4, 6-21.

Mittwoch, U., Dellanty, J. D. A., and Beck, F. (1969). Growth of differentiating testes and ovaries. Nature, 224, 1323-1325.

Naeye, R. L. (1967). Prenatal organ and cellular growth with various chromosomal disorders. Biologia Neonatorum, 11, 248260.

Ohno, S. (1967). Sex Chromosomes and Sex-linked Genes. Springer, Berlin, Heidelberg, and New York.

Penrose, L. S. (1968). Medical significance of finger-prints and related phenomena. British Medical fournal, 2, 321-325.

Penrose, L. S. (1969). Dermatoglyphics. Scientific American, 221, 72-84.

Penrose, L. S. and Smith, G. F. (1966). Down's Anomaly. Churchill, London.

Polani, P. E. (1970). Growing points in cell biology: cytogenetic aspects. Proceedings of the Royal Society of Medicine, 63, 955-959.

Schmid, W. and Leppert, M. F. (1969). Rates of DNA synthesis in heterochromatic and euchromatic segments of the chromosome complements of two rodents. Cytogenetics, 8, 125-135.

Singh, R. P. and Carr, D. H. (1966). The anatomy and histology of XO human embryos and fetuses. The Anatomical Record, 155, 369-383.

Tanner, J. M., Whitehouse, R. H., and Takaishi, M. (1966). Standards from birth to maturity for height, weight, height velocity, and weight velocity: British children, 1965. Archives of Disease in Childhood, 41, 613-635.

Taylor, A. I. (1968). Autosomal trisomy syndromes: a detailed study of 27 cases of Edwards' syndrome and 27 cases of Patau's syndrome. Fournal of Medical Genetics, 5, 227-252.

Van't Hof, J. (1965). Relationships between mitotic cycle duration. $S$ period duration and the average rate of DNA synthesis in the root meristem cells of several plants. Experimental Cell Research, 39, 48-58.

Walker, P. M. B. (1971). Origin of satellite DNA. Nature, 229, 306-308.

Weiss, P. (1955). Nervous system. In Analysis of Development, pp. 346-401, ed. by B. H. Willier, P. A. Weiss, and V. Hamburger. Saunders, Philadelphia and London.

Yang, D. P. and Dodson, E. O. (1970). The amounts of nuclear DNA and the duration of DNA synthetic period (S) in related diploid and autotetraploid species of oats. Chromosoma, 31, 309320. 